УДК: 37

DOI $10.21661 / r-556035$

\title{
А.П. Бутенко
}

\section{ЧТЕНИЕ КАК МОТИВАЦИЯ К ИЗУЧЕНИЮ АНГЛИЙСКОГО ЯЗЫКА В ОБРАЗОВАТЕЛЬНОЙ СРЕДЕ ЛИЦЕЯ (ИЗ ОПЫТА НАЧАЛЬНОЙ ШКОЛЫ)}

Аннотация: статья посвящена особенностям обучения чтению как виду речевой деятельности обучающихся начальной школь. Автором рассмотрень актуальные пути организации развития навыков чтения текстов на английском языке, что приводит к активизаџии саморазвития учащихся в образовательном пространстве лищея.

Ключевые слова: образовательная среда, мотивация, чтение, взаимодействие.

\section{Чтение - это окошко, через которое дети видят и познают мир и самих себя. \\ В. Сухомлинский}

Современный мир цифровых технологий диктуем нам и, соответственно, современным учащимся свои правила, но, несмотря на это, очевидным остается факт, что чтение на уроках английского языка - это важный фактор развития мотивации к изучению не только английского языка, но и изучение культуры, обогащение словарного запаса, это, и, в принципе, как возможность погрузиться в мир сказок, интересной и познавательной информации. Наши дети, к сожалению, считают, что можно читать, используя мобильные устройства, но наша задача- поддерживать интерес к саморазвитию ребят через чтение, чтоб держать книгу в руках и читать так, чтоб чтение приносило удовольствие, стало для них побуждением к саморазвитию.

В образовательном пространстве деятельность учителя регламентируется нормативными документами, важным из которых является Федеральный образовательный стандарт, в данном случаи начального общего образования. 
Следовательно, во главу угла становятся предметные результаты по учебному предмету «Иностранный язык» предметной области «Иностранный язык», которые представлены в данном документе, а именно:

Смысловое чтение: читать вслух и понимать учебные и адаптированные аутентичные тексты объемом до 80 слов, построенные на изученном языковом материале, соблюдая правила чтения и правильную интонацию; читать про себя и понимать основное содержание учебных и адаптированных аутентичных текстов объемом до 160 слов, содержащих отдельные незнакомые слова, не препятствующие решению коммуникативной задачи; определять тему, главную мысль, назначение текста; извлекать из прочитанного текста запрашиваемую информацию фактического характера (в пределах изученного); читать несплошные тексты (простые таблицы) и понимать представленную в них информацию;

Исходя из вышесказанного задачи направлены на то, чтобы научить работать с текстом, понимать прочитанное, научить выделять главную информацию рассказа, а также успешно выполнять задания и с удовольствием осваивать английский язык.

Очевидным является факт, что при выполнении этих задач, мы повысим мотивацию к изучению английского языка и это станет стимулом для саморазвития ребят. Необходимо обратиться к этим понятиям, итак «мотивация - совокупность стойких мотивов, побуждений, определяющих содержание, направленность и характер деятельности личности, ее поведения [1, c. 198]. Бесспорно, благодаря конструктивно выстроенному субъектсубъектному взаимодействию учителя и учащихся, понимая трудности, возникающие в процессе чтения, становится возможным создать условия, в которых процесс чтения литературы на английском языке станет доступным и понятным заданием.

Первым шагом на пути к чтению как процессу, который приносит удовольствие, было проведено анкетирование учащихся, чтобы выявить их интерес у чтению и выполнению заданий после чтения. Итак, анкетирование 
состояло из 3 вопросов, в анкетировании приняли участие 100 ребят (4a, б, в классы лицея). Вопросы и результаты представлены в таблице и диаграммах:

Таблица 1

\begin{tabular}{|l|l|c|c|c|c|}
\hline Участники & \multicolumn{1}{|c|}{ Вопросы } & Да & $\begin{array}{c}\text { Думаю, что } \\
\text { да }\end{array}$ & Не очень & Нет \\
\hline 4 а, б, в & $\begin{array}{l}\text { Нравится ли тебе читать } \\
\text { на английском языке? }\end{array}$ & 38 & 34 & 22 & 6 \\
\hline 4 а, б, в & $\begin{array}{l}\text { Интересно выполнять } \\
\text { задания после чтения? }\end{array}$ & 40 & 36 & 17 & 7 \\
\hline 4 а, б, в & $\begin{array}{l}\text { Хотел бы узнать больше } \\
\text { о Калужской области, } \\
\text { читая тексты на } \\
\text { английском языке? }\end{array}$ & 42 & 32 & 17 & 9 \\
\hline
\end{tabular}

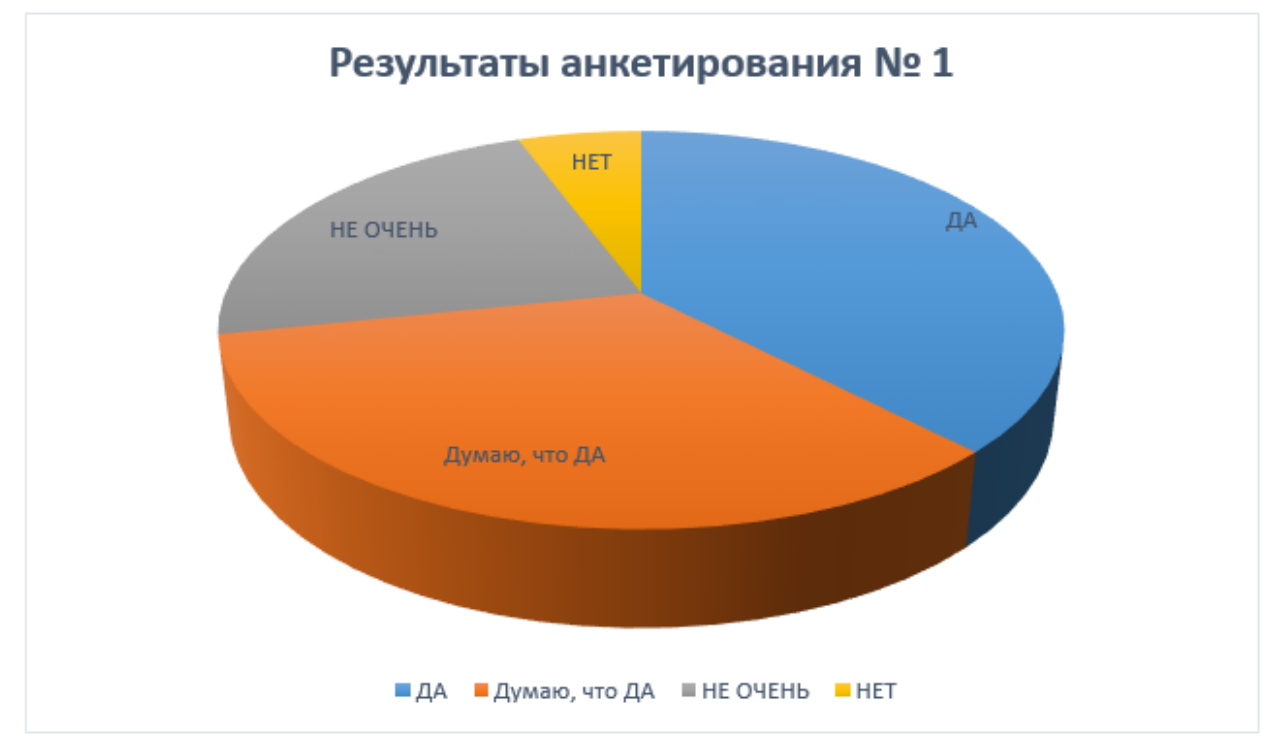

Рис. 1

Мое удивление было приятным и радостным, что ребята начальной школы имеют стойкий мотив к изучению английского языка и моя задача использовать чтение как инструмент повышения мотивации, снятия языкового барьера, чтобы ребята смело и уверенно отвечали на уроках. Анкетирование дало основание использовать на уроках не только тексты учебник Spotlight, но и дополнительную литературу. 


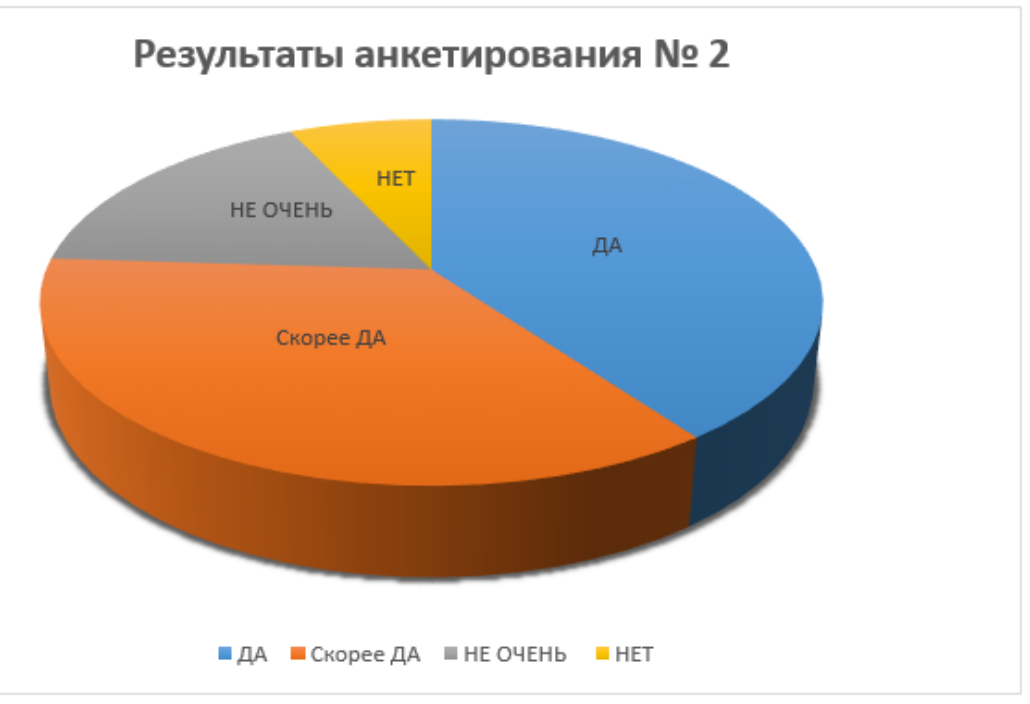

Рис. 2

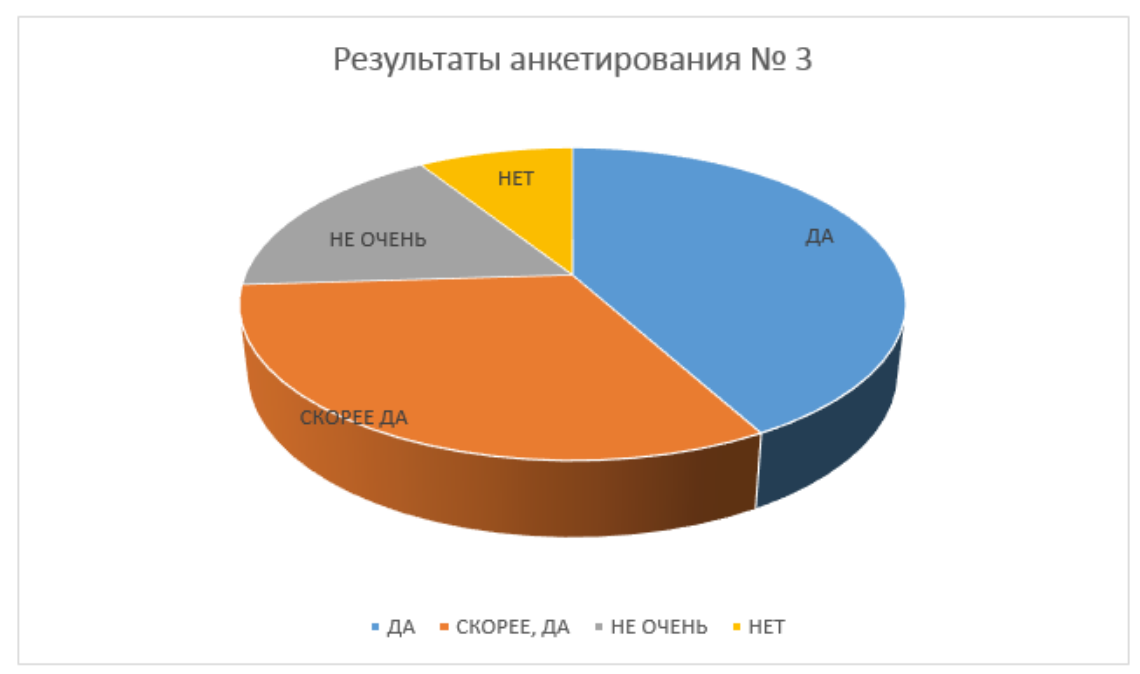

Рис. 3

Итак, перейдем к дальнейшему шагу - это использование пособий и вариантов заданий. Если говорить о Spotlight то, сказку Goldilocks and Three Bears мы обязательно инсценируем и это тот путь, когда снимается языковой барьер, отрабатываются навыки произношения, раскрывается потенциал ребенка через роль. В данном случае задействуется страноведческая мотивация обучающихся, когда появляется «возможность обратить внимание на различные проявления национальных специфических особенностей иной культуры» [4, c. 168].

Дополнительным источником текстов с чтением является учебное пособие Kaluga files для 2-4 классов. Это возможность читать тесты, исследовать и 
познавать родную Калужскую область и возможность закрепить материал при помощи заданий таких как:

- Do the crossword puzzle;

- Answer the questions;

- Fill in the gaps;

- Project (Find a flower in the Red List of Kaluga Region. Make a presentation) и другие не менее интересные упражнения.

При использовании данного пособия развивается краеведческая мотивация и это важный компонент, так как выступает совокупность воспитательной функции и образовательной.

Также мы используем пособие «Easy Stories» для учащихся начальной школы, что делает чтение проработанным, а именно работа с грамматическими формами), работа с лексикой, а также заполнение My reading Log. При использовании этого пособия мы формируем способность совершенствоваться и желание учиться и желание отложить в сторону гаджет, открыть книгу, полистать ее, познакомиться и погрузиться в мир английского языка через чтение и понимать, что это станет импульсом для саморазвития.

Исходя из вышесказанного, хотелось бы подчеркнуть, что при выборе учителем из всего многообразия учебных пособий, таких ресурсов - источники для чтения, которые бы отвечали требованиям ФГОС, способствовали развитию самостоятельности, а также развивали мотивацию к осознанному изучению иностранного языка, чтоб чтение на уроке учителем или ребятами делал это процесс камфорным и побуждал учащихся к формированию желанию читать от маленьких рассказов до книг.

\section{Сиисок литературы}

1. Коджаспирова Г.М. Словарь по педагогике / Г.М. Коджаспирова, А.Ю. Коджаспиров. - М.: МарТ; Ростов н/Д: МарТ, 2005. - 448 с.

2. Обучение иностранным языкам - современные проблемы и решения: сборник материалов I Международной научно-практической конференции 
имени Е. Н. Солововой (5-6 ноября 2019 года) / под ред. М.А. Буровой, А.Е. Буровой и др. - Обнинск: Титул, 2020. - 796 с.

3. Соловова Е.Н. Чтение в составе универсальных учебных действий: позиции ФГОС и традиционной методики обучения иностранным языкам // Иностранные языки в школе. - 2014. - №4. - С. 2-15.

4. Соловова Е.Н. Методика обучения иностранным языкам: базовый курс. М.: Астрель, 2008. - 238 с.

5. Федеральный государственный образовательный стандарт начального общего образования / Министерство образования и науки Российской Федерации. - М.: Просвещение, 2010. - 31 с.

6. Английский язык. 2-4 классы: учеб. пособие для общеобразовательных организаций / М.В. Молокина [и др.]. - М.: Просвещение, 2019. - 112 с.

7. Easy stories $2=$ Простые рассказы 2. Английский язык. Книга для чтения. Учебное пособие / А. Тейлор. - Обнинск, 2020. - 80 с.

Бутенко Анна Петровна - канд. пед. наук, учитель, МБОУ «Лицей №36», Калуга, Россия. 